\title{
METHODOLOGY OF NONDESTRUCTIVE IDENTIFICATION OF DEFECTIVE CONCRETE ZONES IN UNILATERALLY ACCESSIBLE MASSIVE MEMBERS
}

\author{
Tomasz GORZELAŃCZYK, Jerzy HOŁA, Łukasz SADOWSKI, Krzysztof SCHABOWICZ \\ Institute of Building Engineering, Wroclaw University of Technology, Wybrzeże Wyspiańskiego 27, \\ 50-370 Wroclaw, Poland
}

Received 10 Apr 2013; accepted 3 Jun 2013

\begin{abstract}
The paper deals with the nondestructive identification of defective concrete zones in unilaterally accessible massive members, for example, access galleries in hydroelectric power plants. The concrete in such zones is, for various reasons, excessively porous. The authors propose to use state-of-the-art acoustic testing techniques, including ultrasonic tomography, integratively to detect and identify defective zones. An original methodology for such tests has been developed. The methodology is illustrated with an example of its practical application to a real civil engineering structure.
\end{abstract}

Keywords: concrete, durability, water pressure, vibrations, honeycombing, acoustic techniques, nondestructive tests, impulse response, ultrasonic tomography.

Reference to this paper should be made as follows: Gorzelańczyk, T.; Hoła, J.; Sadowski, Ł.; Schabowicz, K. 2013. Methodology of nondestructive identification of defective concrete zones in unilaterally accessible massive members, Journal of Civil Engineering and Management 19(6): 775-786. http://dx.doi.org/10.3846/13923730.2013.812577

\section{Introduction}

The massive members of hydroelectric power plants, dams, and other structures are erected from concrete one of the principal construction materials (Kmiecik, Kamiński 2011; Soutsos et al. 2011; Angst et al. 2012; Musiał 2012). Because of the great thickness and mass of the concrete such structures incorporate they are prone to locally develop defective zones during construction. These are zones in which the concrete mixture was not vibrated. There are also zones in which the concrete mixture contained large aggregate particles, which were not sufficiently enveloped with cement mortar. In such zones, the hardened concrete is excessively porous (honeycombed). The zones are macrononhomogeneities which in extreme cases can locally occupy a volume of up to several cubic meters.

In the course of their service, such structural members are usually simultaneously subjected to unilateral water pressure and vibrations. This applies, for example to the walls of access galleries in hydroelectric power plants. As a result of the continuous vibrations generated by the operating power plant turbines, with time zones of excessively porous state, and so weaker, concrete can interconnect via cracks propagating in the concrete, whereby "paths" pervious to water form across the wall. Water flowing along the "paths" increases the leakiness of the walls. Water dissolves and washes out calcium hydroxide $\left(\mathrm{Ca}(\mathrm{OH})_{2}\right)$ from the hardened cement grout. As lime is being leached, leakiness increases further and the compression strength of the concrete decreases. This adversely affects the durability of the concrete members (Safinowski 2011; Łowińska-Kluge, Błaszczyński 2012; Łydżba et al. 2012).

Water leakages into the gallery make its use difficult. Attempts at sealing the leaking places without a prior reconnaissance aimed at locating the zones of weaker concrete and determining their extent are ineffective at long term, since new leaking places (indicating that new paths of water leakage through the wall have formed) appear besides the already sealed places, as shown in Figure 1. In order to effectively solve the troublesome problem of water leaks it is necessary to detect and locate, adequately early, the defective zones in the unilaterally accessible massive concrete member, at least to a depth of about $1000-1500 \mathrm{~mm}$.

The detection and location of such zones of defective (excessively porous) concrete in members

Corresponding author: Łukasz Sadowski

E-mail: lukasz.sadowski@pwr.wroc.pl 


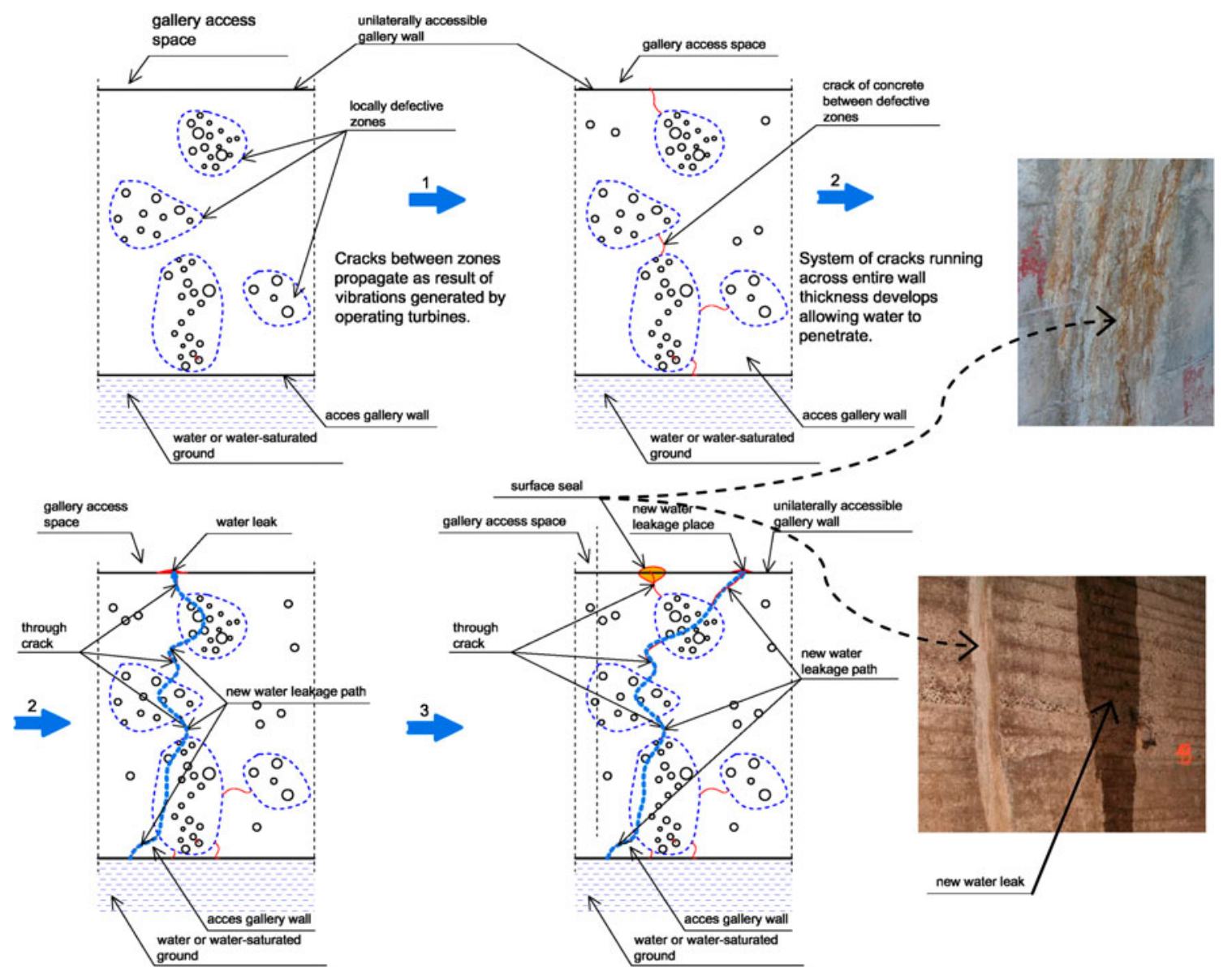

Fig. 1. Hydroelectric power plant access gallery and illustration of how water leaks through its walls arise

accessible from only one side is not easy. Nondestructive acoustic techniques, especially the state-of-the-art impulse response technique (ASTM C1740-10 2010) and ultrasonic tomography (Hoła, Schabowicz 2010; Schabowicz, Hoła 2012), increasingly and often used today to diagnose building structures, can be helpful in this regard (Schickert 2005; Beutel et al. 2008; Maksymowicz et al. 2011; Zwolski, Bień 2011; Goszczyńska et al. 2012; Leibbrandt et al. 2012; Ožbolt et al. 2012).

In this paper the authors propose, on the basis of their research experience to date (Schabowicz et al. 2010; Gorzelańczyk et al. 2012a, b; Schabowicz, Hoła 2012), an original test methodology, integrating the latest nondestructive techniques, for identifying and locating defective zones in unilaterally accessible massive concrete members. The methodology has already been used in practice. An example of its use is provided.

Since the two nondestructive diagnostic techniques have not been commonly used so far, and hence are less known, a concise description of them, necessary to understand the proposed methodology is included.

\section{Survey of literature}

The identification of defects, including excessively porous zones, in unilaterally accessible concrete members by means of ultrasonic tomography, has been studied, among others by Bishko et al. (2008), Kozlov et al. (1997), Samokrutov et al. (2002, 2006), Samokrutov, Shevaldykin (2011) and Shevaldykin et al. (2003). Also in Bishko (2007) the nondestructive ultrasonic tomography method was recommended for identifying defects in concrete members. Stawiski (2012) used the nondestructive ultrasonic method and point probes to identify concrete nonhomogeneities in horizontally formed members. Quiviger et al. (2010) proposed to use the nondestructive ultrasonic echo method to identify macrononhomogeneities and macrocracks in concrete members. In Garbacz and Piotrowski (2010), Krause et al. (2005) and Taffe, Wiggenhauser (2006) it is proposed to use the impactecho method for this purpose. In Davis (2003), Davis et al. (1996) Hertlein, Davis (1998) and Ottosen et al. (2004) the nondestructive impulse response method is recommended for locating defects in concrete 
members. The above authors studied relatively thin concrete members, each time using a single nondestructive method.

In the literature, one cannot find any study dealing with the identification and location of defects in the form of excessively porous concrete in unilaterally accessible massive concrete members, for which purpose, at least two of the above nondestructive acoustic methods, for example, the impulse response method and the ultrasonic tomography method, would be used sim ultaneously. Although the authors Kurz et al. (2012) and Huston et al. (2011) came up with an idea of the integrated use of the methods, the experiments they conducted were not directly connected with the location of zones of excessively porous concrete.

The present authors' research indicates that the nondestructive acoustic methods of impulse response and ultrasonic tomography when used integratively, complement each other. Owing to this they can be useful in identifying and locating defective zones (concrete macrononhomogeneities) in massive members accessible from only one side. The impulse response method is suitable for the fast searching of defects in large concrete surfaces and enables one to approximately identify and locate such defects in up to $1500 \mathrm{~mm}$ thick members, but the depth at which a defect occurs cannot be directly assessed. This possibility is offered by ultrasonic tomography, enabling one to identify and spatially locate defects in massive members with a thickness of up to $2500 \mathrm{~mm}$.

\section{Concise description of nondestructive methods integrated in proposed methodology}

Table 1 presents basic information on the impulse response method, including: a brief description, a schematic of the test setup, the registered parameters, and sample tests results. A more comprehensive description of this test method can be found in Hoła, Schabowicz (2010) and Hoła et al. (2011).

Table 2 presents basic information on the ultrasonic tomography method. A more comprehensive description of this method can be found in Hoła, Schabowicz (2010) and Schabowicz, Hoła (2012).

\section{Proposed methodology of nondestructive tests}

The methodology proposed for the nondestructive identification and location of defective (macrononhomogeneities) concrete zones in unilaterally accessible massive members through the integrated use of stateof-the-art acoustic methods of impulse response and ultrasonic tomography is graphically presented in Figures 2 and 3 and described below.

As Figure 3 shows, it is proposed to carry out the investigations in two stages.
In stage I, the impulse response method is used to identify and superficially locate defective concrete zones present in the tested member.

For this purpose $i$ measuring places should be marked on the tested concrete member. In each of the places one should mark a grid of $n$ measuring points spaced at every $1000 \mathrm{~mm}$, keeping a minimum distance of $500 \mathrm{~mm}$ from the edge of the tested member. If the surface area of the latter is very large one can increase the spacing to $2000 \mathrm{~mm}$. The maximum testing range, that is the distance from the surface, amounts to about $1500 \mathrm{~mm}$.

Then an elastic wave is generated by striking with the calibrated hammer in each point of the marked measuring grid, and after each strike the value of elastic force $F$ generated by the hammer, the diagram of elastic wave velocity $w$ and the diagram of mobility $N$ are analyzed. The conditions, the satisfaction of which guarantees satisfactory reliability of the obtained results are specified in ASTM C174010 (2010), Hoła et al. (2011) and Hertlein, Davis (1998).

If the results are found to be satisfactory, they should be processed using the dedicated software. In this way the values of the characteristic parameters, that is average mobility $N_{a v}$ stiffness $K_{d}$, mobility slope $M_{p}$, mobility times mobility slope $N_{a v} \cdot M_{p}$, and voids index $w$, in each of the measuring grid points are obtained. Then maps showing the distribution of the parameter values on the surface of the tested member should be plotted.

The final step in this stage is a detailed analysis of the maps, the aim of which is to approximately identify the zones where it is highly probable that defects occur.

Then one should move to stage II of the investigations, using the ultrasonic tomography method to confirm the defects detected by the impulse response method and to locate them along the depth of the tested member.

First, $k$ measuring bands should be marked in the zones found to be defective. At least one measuring band with a minimal width equal to that of the measuring antenna and having the desired length should be marked in each such zone. Depending on the type of the antenna, the band is 380 or $500 \mathrm{~mm}$ wide while its length may amount to several meters.

Then one should calibrate the tomograph by measuring the velocity of the ultrasonic wave (signal) in a given zone several times and determining its average value.

Subsequently, one should measure the velocity of this wave in each antenna application place in each of the bands. In the course of the measurement the ultrasonic signals should be preliminarily analyzed to determine whether the defect can be identified on their basis. If this is not the case, the test should be repeated. If the answer is yes, the signals should be 
Table 1. Concise description of impulse response method (Davis et al. 1996; Hertlein, Davis 1998; Davis 2003; Ottosen et al. 2004)

\section{Description of method}

The impulse response method consists in exciting an elastic ultrasonic wave in the tested member by means of a calibrated hammer with a rubber tip. The frequency of the excited wave is in a range of $1-800 \mathrm{~Hz}$, while the range of excitation around the test point amounts to $1000 \mathrm{~mm}$. The method is suitable for the approximate location of areas in which defective zones in the form of concrete nonhomogeneities may occur in unilaterally accessible members, to a depth of about $1500 \mathrm{~mm}$.

\section{Schematic of test setup}

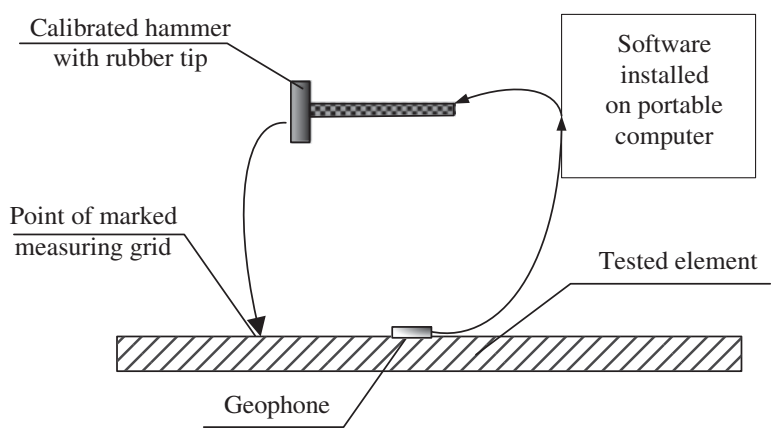

Test procedure

Calibrated hammer strikes are delivered in selected test points of a grid of, for example, $1000 \times 1000 \mathrm{~mm}$, squares marked on the surface of the tested member. The signal of the elastic wave propagating in the member is registered by a geophone and amplified. The signals recorded in the course of the test are processed using dedicated software installed on a portable computer. In this way the values of five parameters are obtained.

\section{Registered parameters}

In each test point the values of the following parameters are registered:

- average mobility $N_{\text {av }}$;

- stiffness $K_{\mathrm{d}}$;

- mobility slope $M_{\mathrm{p}} / N$;

- mobility times mobility slope $N_{\mathrm{av}} \cdot M_{\mathrm{p}} / N$;

- voids index $v$.

Maps showing the distribution of the above parameters on the surface of the tested member are plotted on this basis.

\section{Sample results and their analysis}

Typical maps showing the distribution of the registered parameters on the surface of the tested member are presented as follows:
Table 1. (Continued)

Sample results and their analysis
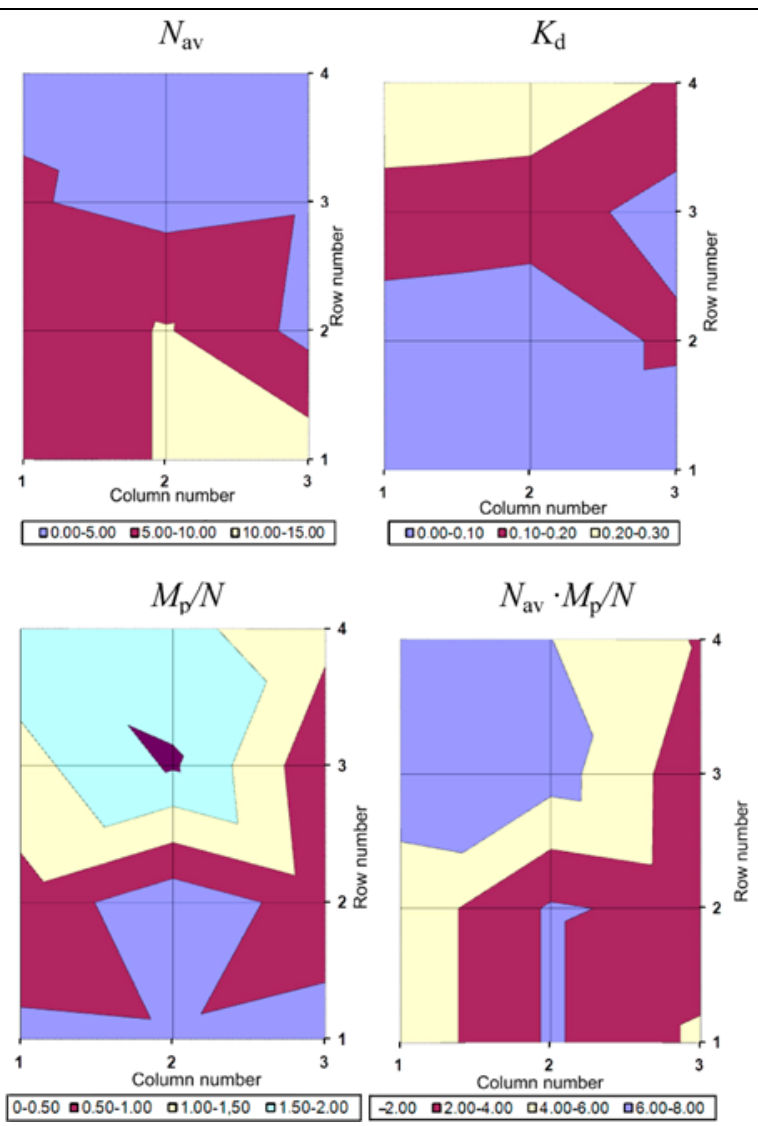

$\begin{array}{llllllllll}0-0.50 & \mathbf{0} 0.50-1.00 & \mathbf{0} 1.00-1,50 & 01.50-2.00 & -2.00-4.00 & 04.00-6.00 & 06.00-8.00\end{array}$

An analysis of the parameter values is carried out, considering that, for example,

- a local increase in the value of parameter $N_{\mathrm{av}}$ in a given test point may indicate a smaller thickness of the member in this point or a nonhomogeneity in the concrete;

- a local decrease in the value of $K_{\mathrm{d}}$ in a test point may indicate a nonhomogeneity in the concrete there, a delamination of layers, and so on;

- a high value of parameter $M_{\mathrm{p}} / N$ is closely connected with the presence of defects, for example, delaminations in the cross section of the tested member or an inadequate interlayer bond;

- if parameter $N_{\mathrm{av}} \cdot M_{\mathrm{p}} / N$ reaches a value higher than $310^{-7} \mathrm{~m} / \mathrm{s} \cdot \mathrm{N}$ this means that a defective area occurs in the tested place;

- if the value of coefficient $v$ is higher than 2, this may indicate a defective area.

processed using the dedicated software. The processing consists in assembling the data recorded for a given measuring band.

If the results are satisfactory, they are recorded and flat images B-D, showing the inside of the concrete member in the given zone, in three mutually perpendicular directions are obtained. The defective 
Table 2. Concise description of ultrasonic tomography method (Kozlov et al. 1997; Bishko 2007; Bishko et al. 2008)

\section{Description of method}

The ultrasonic tomography method consists in exciting an elastic wave in the tested member. The exciter is a multihead antenna (incorporating tens of integrated ultrasonic heads) which is also used to receive and process ultrasonic signals. The heads generate ultrasonic pulses with a frequency of $50 \mathrm{kHz}$. The maximum test range amounts to $2500 \mathrm{~mm}$ of the tested member thickness.

The tomograph has been designed to determine the thickness of unilaterally accessible concrete member and to detect cracks, inclusions, air voids, and other places which may be empty or filled with a liquid or a material differing in its density and other physical mechanical properties from the surrounding concrete.

Schematic of test setup

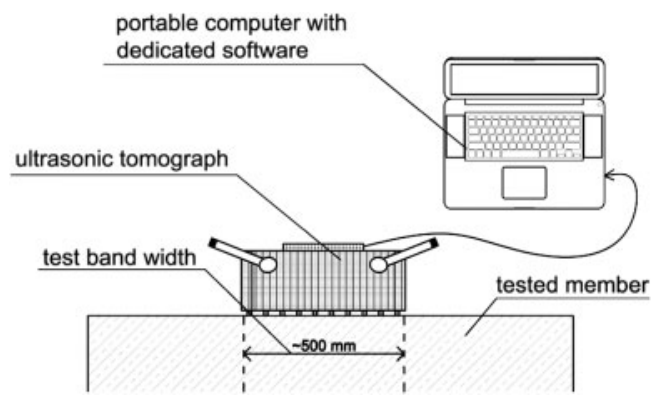

\section{Test procedure}

In the course of the test the ultrasonic tomograph antenna is moved stepwise (at a step of $100 \mathrm{~mm}$ ) in the same direction in a given $380 \mathrm{~mm}$ or $500 \mathrm{~mm}$ wide (depending on the antenna type) test band. The obtained results, in the form of images of the cross sections in each antenna position, are collected in a three-dimensional matrix table. Using this matrix table and the dedicated software installed on a portable computer one obtains three images B-D in three mutually perpendicular directions, as shown in the following figure:

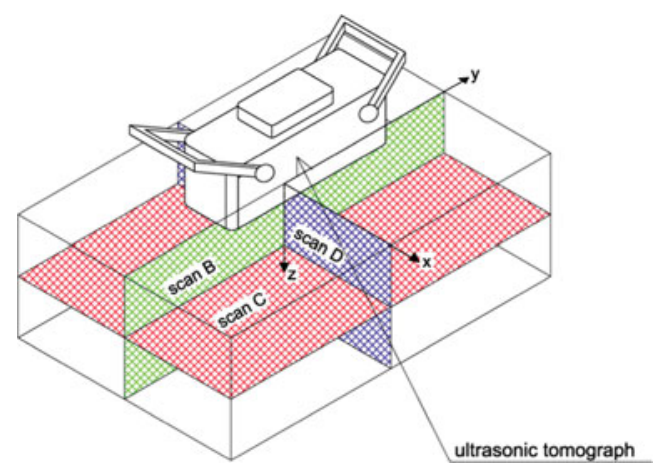

Table 2. (Continued)

\section{Results and their interpretation}

Using this method one obtains three mutually perpendicular images B-D in each of the 380 or $500 \mathrm{~mm}$ wide test band and an ultrasonic dispersion level color scale assigned to the images, as shown in the following figure:

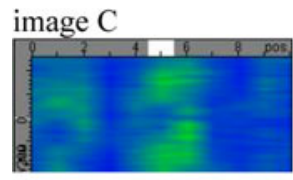

ultrasonic dispersion scale
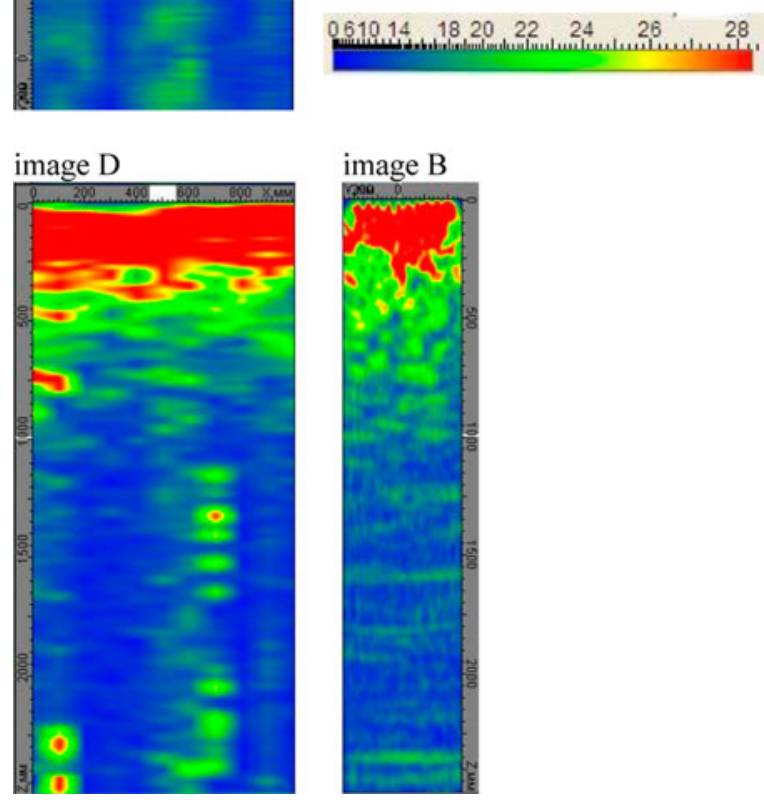

The interpretation of the obtained results comes down to the analysis of the images. From the differences in the level of ultrasonic dispersion one can infer whether the physical characteristics of the media differ or do not differ from each other in the tested area, which means that one can infer whether within the tested band there is a material (air voids, concrete zones of different density, large inclusions, etc.) whose density is different than that of the concrete.

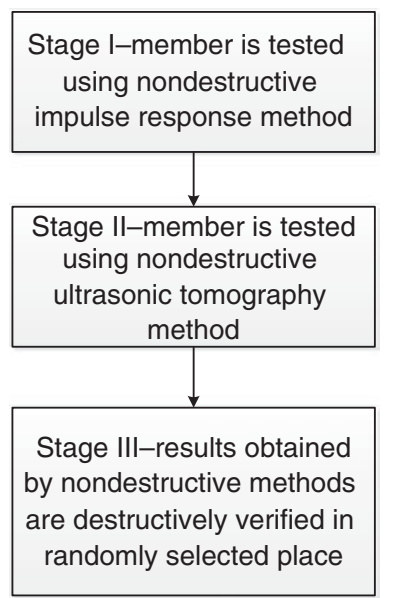

Fig. 2. Hydroelectric power plant access gallery and illustration of how water leaks through its walls arise 


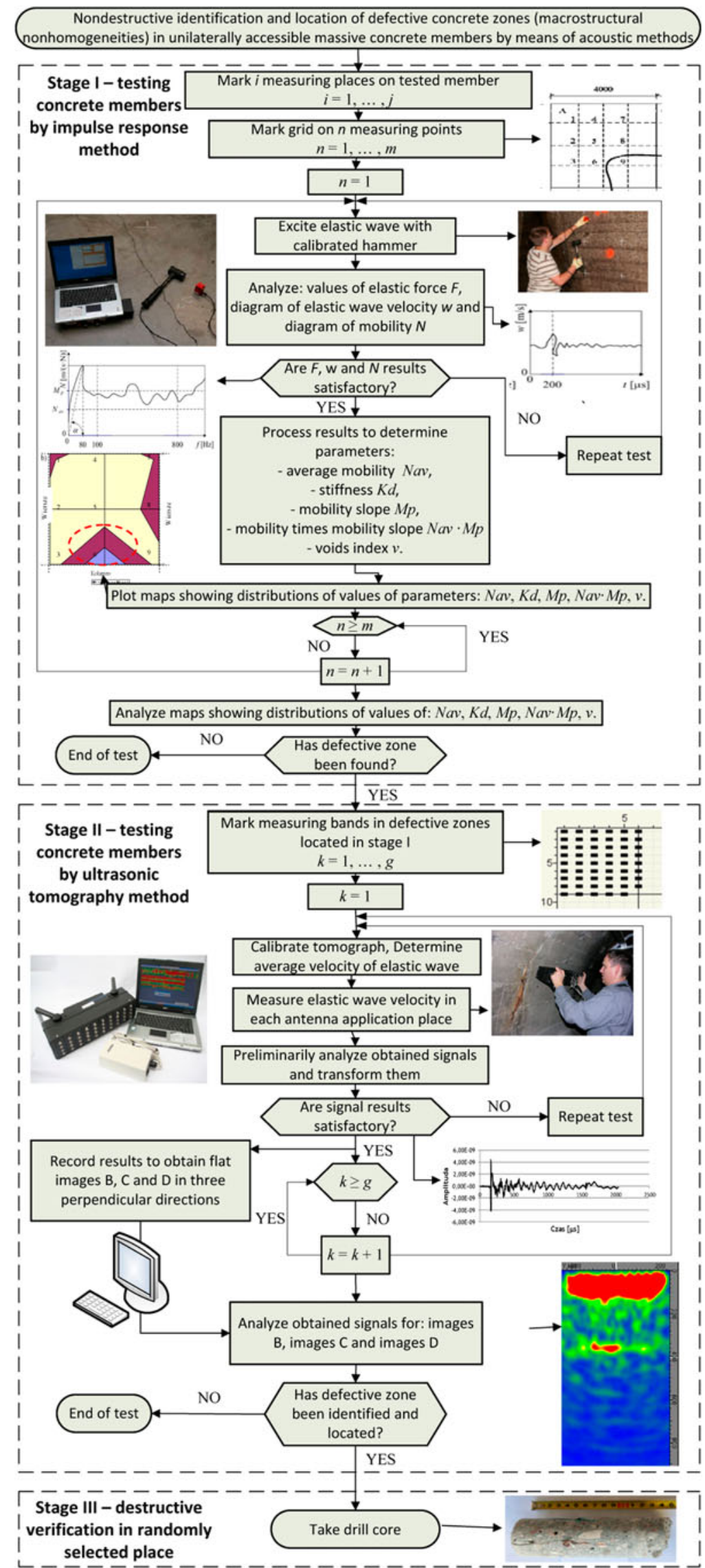

Fig. 3. Flow chart illustrating methodology of nondestructive identification and location of defective zones in unilaterally accessible massive concrete members by means of impulse response and ultrasonic tomography methods 


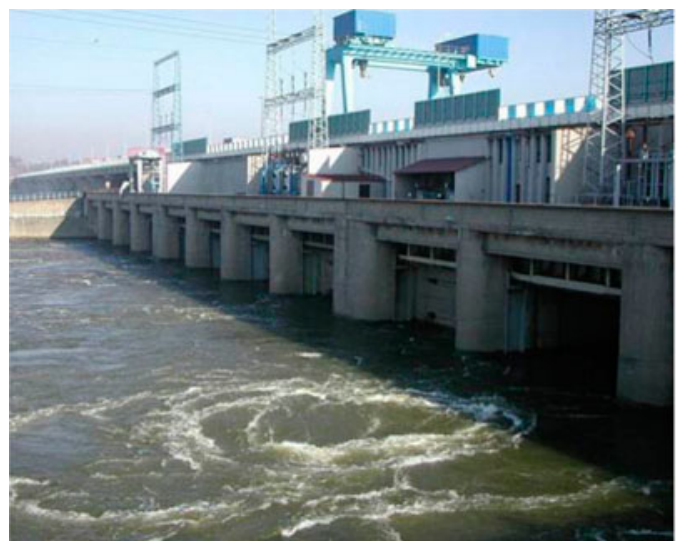

a)

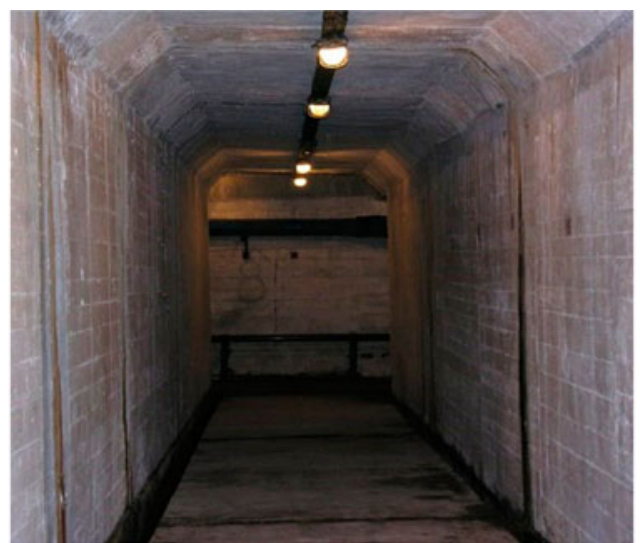

b)

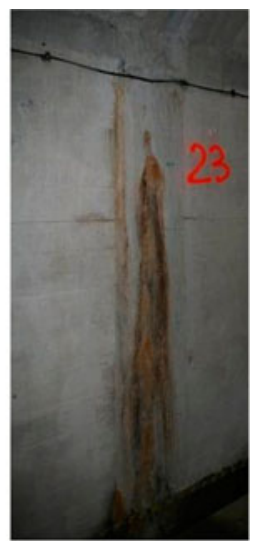

c)

Fig. 4. View of: (a) hydroelectric power plant; (b) access gallery; (c) water leakage on gallery wall

concrete zone can be identified and located along the depth of the tested member through a detailed analysis of images $B$ and D. Image $C$ helps to determine more precisely the depth at which the defect occurs.

In stage III it is recommended to do a destructive verification, for example, by taking a drill core.

\section{Example of practical use of proposed methodology}

The proposed methodology was used in practice to locate and identify defective zones of concrete in a massive access gallery in a hydroelectric power plant. The tests were carried out in connection with a planned renovation of the power plant. Figure 4 shows the power plant, the access gallery, and a close up of a water leakage on the gallery wall.

\subsection{Description of tested wall}

During their operation the turbines (each with a power of a few tens of megawatts) make the massive concrete members (including the access gallery walls) vibrate. The gallery walls are made of $\mathrm{C} 25 / 20$ grade concrete with a maximum aggregate size of $32 \mathrm{~mm}$ and since they are situated below the water level they should be leakproof. Despite the repeated local sealing, new leaks keep on appearing.

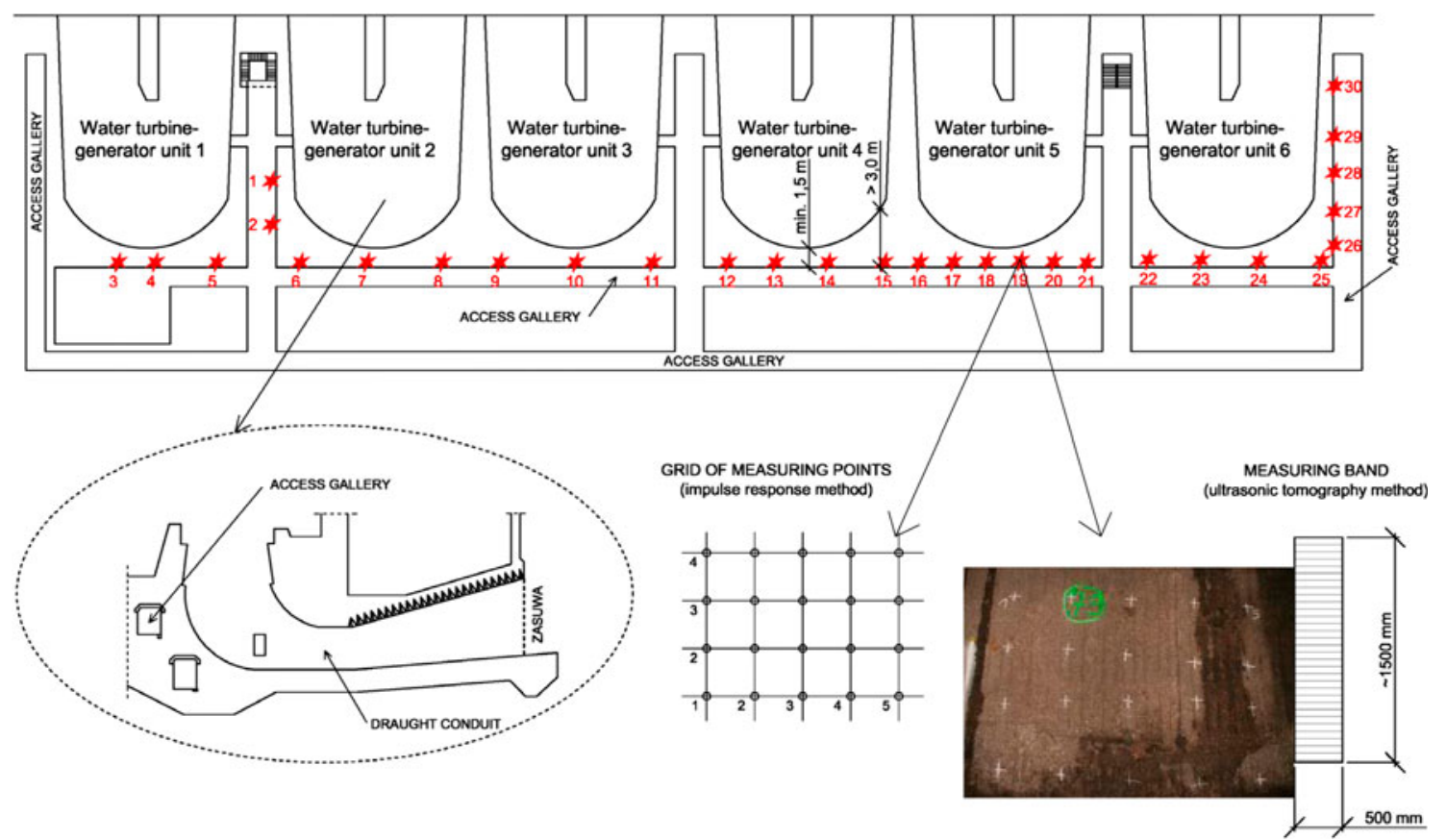

Fig. 5. Location and numbers of measuring places on tested access gallery wall 
Table 3. Sample values of characteristic parameters, determined by impulse response method

\begin{tabular}{|c|c|c|c|c|c|c|}
\hline \multirow[b]{2}{*}{ No. } & \multirow{2}{*}{$\begin{array}{l}\text { Number of measuring } \\
\text { place/(row no. - column no.) }\end{array}$} & \multicolumn{5}{|c|}{ Parameter symbol } \\
\hline & & $N_{\text {av }}(\mathrm{m} / \mathrm{s} \cdot \mathrm{N})$ & $K_{\mathrm{d}}(-)$ & $M_{\mathrm{p}} / N(-)$ & $N_{\mathrm{av}} \cdot M_{\mathrm{p}} / N(\mathrm{~m} / \mathrm{s} \cdot \mathrm{N})$ & $v(-)$ \\
\hline 1 & $1 /(1-1)$ & 1.194 & 0.069 & 51.294 & 1.417 & 0.410 \\
\hline 2 & $1 /(1-2)$ & 1.022 & 0.039 & 43.399 & 1.312 & 0.505 \\
\hline 3 & $1 /(1-3)$ & 0.695 & 0.069 & 70.227 & 1.258 & 0.547 \\
\hline 4 & $1 /(1-4)$ & 0.367 & 0.050 & 48.984 & 0.920 & 0.536 \\
\hline 5 & $1 /(1-5)$ & 0.677 & 0.080 & 65.684 & 2.569 & 1.391 \\
\hline 6 & $1 /(1-6)$ & 0.637 & 0.087 & 86.766 & 2.628 & 2.449 \\
\hline 7 & $1 /(1-7)$ & 0.520 & 0.085 & 257.087 & 0.783 & 2.751 \\
\hline 8 & $1 /(1-8)$ & 0.293 & 0.116 & 344.710 & 1.160 & 2.081 \\
\hline 9 & $1 /(1-9)$ & 3.835 & 0.010 & 135.950 & 1.281 & 0.449 \\
\hline 10 & $1 /(1-10)$ & 3.667 & 0.030 & 238.160 & 1.115 & 0.644 \\
\hline$\vdots$ & $\vdots$ & $\vdots$ & $\vdots$ & ! & $\vdots$ & $\vdots$ \\
\hline 1050 & $30 /(4-5)$ & 2.436 & 0.050 & 67.180 & 0.735 & 0.298 \\
\hline
\end{tabular}

Table 4. Sample test results in form of maps showing distribution of values of parameters $N_{\mathrm{av}}, K_{\mathrm{d}}$, determined in measuring points 3 and 23 by impulse response method

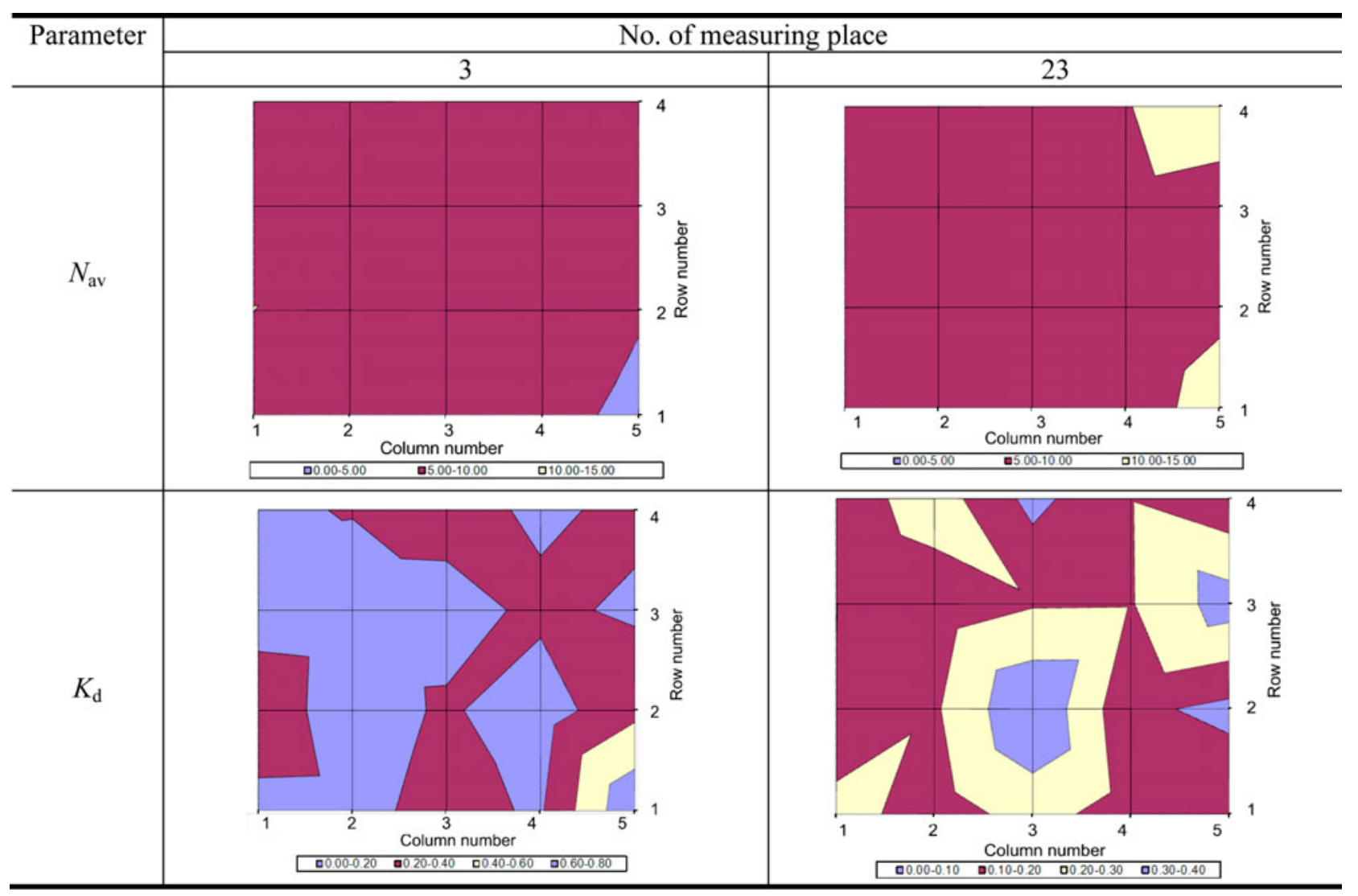

The massive concrete gallery wall, accessible from only one side, was tested in 30 measuring places along its entire length using the proposed methodology. The location and numbers of the places are shown in Figure 5. A grid (4-5 rows and 3-11 columns) of measuring points (in total 1050 measuring points along the entire length of the wall) was marked in each measuring place. The distance between the measuring points amounted to about $500 \mathrm{~mm}$.
The tests were carried out in accordance with the methodology described in Section 4, using first the impulse response method and then the ultrasonic tomography method.

\subsection{Results of tests}

In the course of testing by the impulse response method in each of the measuring points an elastic 
Table 5. Sample test results for measuring places no. 3 and 23, obtained by ultrasonic tomography method

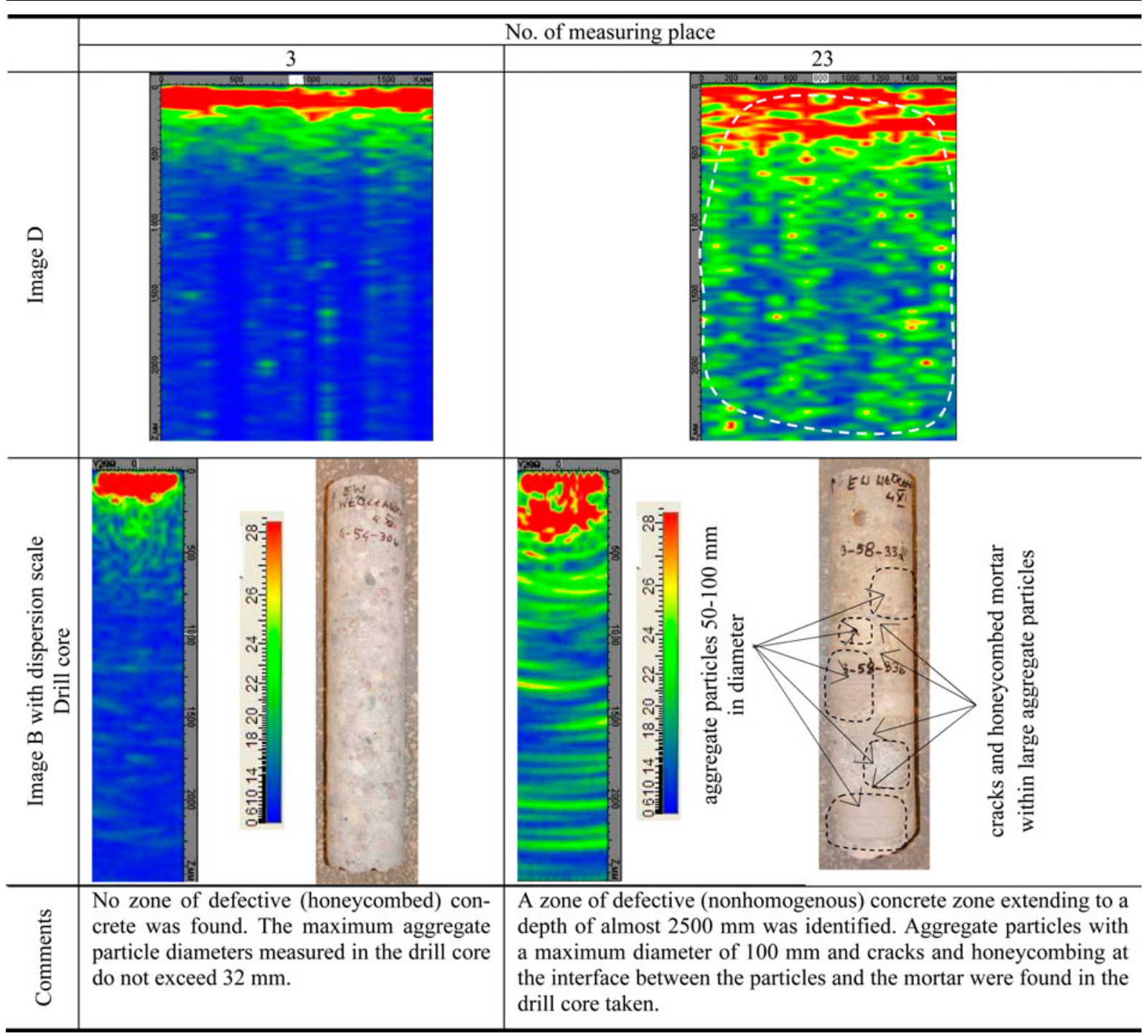

wave was excited using a special rubber-tipped hammer and the values of the characteristic parameters: average mobility $K_{d}$, mobility slope $M_{p}$, average mobility times mobility slope $N_{a v} \cdot M_{p}$, and voids ratio $v$ were determined. Sample parameter values determined in 10-20 measuring points are presented in Table 3. On the basis of the parameter values in all the measuring points, maps showing the distribution of the parameter values were plotted. Sample maps for measuring points 3 and 23 are presented in Table 4.

It appears from Table 4 that in almost the whole measuring place no. 3 the value of parameter $N_{\mathrm{av}}$ is high, ranging from 5 to $10 \mathrm{~m} / \mathrm{s} \cdot \mathrm{N}$, whereas within measuring point $5-1$ its value is low, ranging from 0 to $5 \mathrm{~m} / \mathrm{s} \cdot \mathrm{N}$. At the same time the value of parameter $K_{\mathrm{d}}$ is high, ranging from 0.4 to 0.8 in most of the measuring place. Therefore, it can be concluded that in measuring place no. 3 a defect in the form of concrete nonhomogeneity is unlikely to occur. This conclusion is confirmed by the map of the distribution of the characteristic parameters, shown in Table 4.

Table 4 also shows that the value of parameter $N_{\mathrm{av}}$ is high in almost the whole measuring place no. 23 , ranging from 5 to $10 \mathrm{~m} / \mathrm{s} \cdot \mathrm{N}$, and within measuring points $5-1$ and 5-4 it is very high, ranging respectively from 10 to $15 \mathrm{~m} / \mathrm{s} \cdot \mathrm{N}$. The value of parameter $K_{\mathrm{d}}$ is very low, ranging from 0 to 0.2 in most of the measuring place, except for measuring point 3-2 where this parameter ranges from 0.3 to 0.4 . On this basis and from an analysis of the map showing the distribution of the characteristic parameters (Table 4) one can conclude that in measuring place no. 23 a defect in the form of a concrete nonhomogeneity is very likely to occur.

Analyses of the results obtained in 30 measuring places showed that, similarly as in the case of measuring place no. 3 , in 16 other tested places there are no reservations about the quality of the concrete. 
Whereas in 13 tested places, as shown for test place no. 23 , defective zones characterized by high concrete nonhomogeneity occur.

Then, in accordance with the proposed methodology, tests were carried out using the nondestructive ultrasonic tomography method. Their aim was to confirm the presence of the defective concrete zones previously detected by the impulse response method and locate them along the depth. The tests were carried out in the measuring places in which defective zones had been located in investigation stage I. In each of the zones, three measuring bands, each $500 \mathrm{~mm}$ wide and $1500 \mathrm{~mm}$ long, were marked.

Sample test results obtained using the ultrasonic tomograph, showing images $\mathrm{B}$ and $\mathrm{D}$ in measuring place no. 3 (deemed not defective) and in the defective zones (measuring place no. 23) are presented in Table 5. The defective concrete zone identified in measuring place no. 23 is marked with a dotted line in image D. Table 5 also contains photographs showing the results of exposure in the form of drill cores taken from measuring places 3 and 23. The bottom row of Table 5 contains comments stemming from the investigations.

The results obtained using the ultrasonic tomography method confirmed the results, which had been obtained by the impulse response method. As shown for test place no. 23, the presence of highly porous and nonhomogenous concrete zones was confirmed in 13 of the test places. In the particular zones, the defects were located along the depth of the tested member.

\section{Conclusions}

A novel methodology integrating the state-of-the-art acoustic methods of impulse response and ultrasonic tomography for the nondestructive identification and location of zones of defective (honeycombed) concrete in unilaterally accessible massive members has been presented. Since the above nondestructive methods are not commonly used for testing, whereby they are less known, the presentation of the methodology was preceded by a concise description of the methods in order to facilitate their understanding.

Three stages are distinguished in the proposed methodology. In stage I, in which tests are carried out using the nondestructive impulse response method, defective zones in the tested member are identified and superficially located. In stage II, in which tests are carried out using the nondestructive ultrasonic tomography method, the defects detected by the impulse response method in stage I are confirmed and located along the depth of the tested member. In stage III, the results obtained by the nondestructive methods are destructively verified in a randomly selected place.
The provided example of the application of the methodology to a real civil engineering structure has shown the methodology to be useful for identifying and locating defective concrete zones in the unilaterally accessible massive wall of the gallery in the hydroelectric power plant.

\section{References}

Angst, U.; Elsener, B.; Jamali, A.; Adey, B. 2012. Concrete cover cracking owing to reinforcement corrosion theoretical considerations and practical experience, Materials and Corrosion 63(12): 1069-1077.

ASTM C1740-10. 2010. Standard practice for evaluating the condition of concrete plates using the impulseresponse method. USA, West Conshohocken, PA: American Society for Testing and Materials (ASTM). 9 p.

Beutel, R.; Reinhardt, H.; Grosse, C.; Glaubitt, A.; Krause, M.; Maierhofer, C.; Algernon, D.; Wiggenhauser, H.; Schickert, M. 2008. Comparative performance tests and validation of NDT methods for concrete testing, Journal of Nondestructive Evaluation 27(1-3): 59-65. http://dx.doi.org/10.1007/s10921-008-0037-1

Bishko, A. 2007. Improvement of imaging at small depths for acoustic tomography of reinforced concrete objects, in The 6th International Conference Non-Destructive Testing and Technical Diagnostics in Industry, 15-17 May, 2007, Moscow, Russia. Abstracts book, Vol. 1. Moscow: Mashinostroenie.

Bishko, A.; Samokrutov, A.; Shevaldykin, A. 2008. Ultrasonic echo-pulse tomography of concrete using shear waves low-frequency phased antenna arrays, in the 17th World Conference on Nondestructive Testing, 25-28 October, 2008, Shanghai, China. 9 p.

Davis, A. 2003. The non-destructive impulse response test in North America: 1985-2001, NDT\&E International 36(4): 185-193.

http://dx.doi.org/10.1016/S0963-8695(02)00065-8

Davis, A.; Hertlein, B.; Lim, K.; Michols, K. 1996. Impactecho and impulse response stress wave methods: advantages and limitations for the evaluation of highway pavement concrete overlays, in Proc. of Conference on Nondestructive Evaluation of Bridges and Highways, 13 November, 1996, Scottsdale, Vol. 2946. 7 p.

Garbacz, A.; Piotrowski, T. 2010. Zastosowanie metody impact-echo do szacowania grubości posadzek betonowych [Application of impact-echo method to identify the concrete floor thickness], Materialy Budowlane 9: 18-19.

Gorzelańczyk, T.; Hoła, J.; Schabowicz, K. 2012a. Nondestructive tests aimed at determining the thickness of the concrete shell of a heat pipe carrying tunnel, in 18th World Conference on Nondestructive Testing, 16-20 April, 2012, Durban, South Africa. 8 p.

Gorzelańczyk, T.; Hoła, J.; Sadowski, Ł.; Schabowicz, K. 2012b. Evaluation of concrete homogeneity in massive structural element of hydroelectric power plant by means of nondestructive ultrasonic tomography method, in Proc. of the 42nd International Conference "Defektoskopie", 30 October-1 November, 2012, Seč u Chrudimi, Czech Republic, 71-76. 
Goszczyńska, B.; Świt, G.; Trạmpczyński, W.; Krampikowska, A.; Tworzewska, J.; Tworzewski, P. 2012. Experimental validation of concrete crack identification and location with acoustic emission method, Archives of Civil and Mechanical Engineering 12(1): 23-28. http://dx.doi.org/10.1016/j.acme.2012.03.004

Hertlein, B.; Davis, A. 1998. Locating concrete consolidation problems using the nondestructive impulse response test, in American Concrete Institute Fall Convention, Los Angeles, October, 1998. 22 p.

Hoła, J.; Schabowicz, K. 2010. State-of-the-art nondestructive methods for diagnostics testing of building structures - anticipated development trends, Archives of Civil and Mechanical Engineering 10(3): 5-18. http://dx.doi.org/10.1016/S1644-9665(12)60133-2

Hoła, J.; Sadowski, Ł.; Schabowicz, K. 2011. Nondestructive identification of delaminations in concrete floor toppings with acoustic methods, Automation in Construction 20(7): 799-807. http://dx.doi.org/10.1016/j.autcon.2011.02.002

Huston, D.; Cui, J.; Burns, D.; Hurley, D. 2011. Concrete bridge deck condition assessment with automated multisensor techniques, Structure and Infrastructure Engineering: Maintenance, Management, Life-Cycle Design and Performance 7(7-8): 613-623.

Kmiecik, P.; Kamiński, M. 2011. Modelling of reinforced concrete structures and composite structures with concrete strength degradation taken into consideration, Archives of Civil and Mechanical Engineering 11(3): 623-636.

http://dx.doi.org/10.1016/S1644-9665(12)60105-8

Kozlov, V.; Samokrutov, A.; Shevaldykin, V. 1997. Thickness measurements and flaw detection in concrete using ultrasonic echo method, Journal of Nondestructive Testing and Evaluation 13(2): 73-84.

http://dx.doi.org/10.1080/02780899708953020

Krause, M.; Milmann, B.; Niederleithinger, E. 2005. Assessment of foundation slabs with USecho in the re-use process, in Proc. of the International Conference on Concrete Repair, Rehabilitation and Retrofitting (ICCRRR), 2005, Cape Town, South Africa, 525-530.

Kurz, J.; Stoppel, M.; Taffe, A.; Boller, C. 2012. Condition assessment of reinforced concrete structures using automated multi-sensor systems, in 18th World Conference on Nondestructive Testing, 16-18 April, 2012, Durban, South Africa. CD-ROM.

Leibbrandt, A.; Caprari, G.; Angst, U.; Siegwart, R.; Flatt, R.; Elsener, B. 2012. Climbing robot for corrosion monitoring of reinforced concrete structures, in Proc. of the 2nd International Conference on Applied Robotics in the Power Industry (CARPI 2012), 11-13 September, 2012, Zurich, Switzerland, 10-15.

Maksymowicz, M.; Cruz, P.; Bień, J. 2011. Load capacity of damaged RC slab spans of railway-bridges, Archives of Civil and Mechanical Engineering 11(4): 963-978. http://dx.doi.org/10.1016/S1644-9665(12)60089-2

Łowińska-Kluge, A.; Błaszczyński, T. 2012. The influence of internal corrosion on the durability of concrete, Archives of Civil and Mechanical Engineering 12(2): 219-227. http://dx.doi.org/10.1016/j.acme.2012.03.002
Łydżba, D.; Różański, A.; Sobótka, M. 2012. An annual cycle of changes in water temperature as a cause of cracking in massive concrete hydraulic structures, AGH Journal of Mining and Geoengineering 36(2): 217-227.

Musiał, M. 2012. Static and dynamic stiffness of reinforced concrete beams, Archives of Civil and Mechanical Engineering 12(2): 186-191. http://dx.doi.org/10.1016/j.acme.2012.04.005

Ottosen, N.; Ristinmmaa, M.; Davis, A. 2004. Theoretical interpretation of impulse response tests of embedded concrete structures, Journal of Engineering Mechanics 130(9): 1062-1071. http://dx.doi.org/10.1061/(ASCE)0733-9399(2004)130: 9(1062)

Ožbolt, M.; Rukavina, T.; Domitrović, J. 2012. Comparison of the pavement layers thickness measured by georadar and conventional methods - examples from Croatia, The Baltic Journal of Road and Bridge Engineering 7(1): 30-35. http://dx.doi.org/10.3846/bjrbe.2012.04

Quiviger, A.; Zardan, J.; Payan, C.; Chaix, J.; Garnier, V.; Moysan, J.; Jean Salin, J. 2010. Macro crack characterization by linear and nonlinear ultrasound in concrete, Proceedings of Meetings on Acoustics 10: 045003.

Samokrutov, A.; Kozlov, V.; Shevaldykin, V.; Meleshko, I. 2002. Ultrasonic defectoscopy of concrete by means of pulseecho technique, in Proc. of the 8th European conference for Non-Destructive Testing, 2002, Madrid, Spain. Madrid: Spanish Society for NDT, 1-9. CD-ROM.

Samokrutov, A.; Kozlov, V.; Shevaldykin, V. 2006. Ultrasonic testing of concrete objects using dry acoustic contact. Methods, instruments and possibilities, in The 5th International Conference "Non-Destructive Testing and Technical Diagnostics in Industry”, 16-19 May, 2006, Moscow, Russia. Abstracts book. Moscow: Mashinostroenie. $152 \mathrm{p}$.

Samokrutov, A.; Shevaldykin, V. 2011. Ultrasonic tomography of metal structures using the digitally focused antenna array method, Russian Journal of Nondestructive Testing 47(1): 16-29. http://dx.doi.org/10.1134/S1061830911010098

Safinowski, P. 2011. Diagnostic ultrasonore de la dégradation mécanique et structurale du béton [Ultrasonic diagnostics of mechanical and structural degradation of concrete]: PhD Thesis, Université Lille Nord-de-France.

Schabowicz, K.; Hoła, J.; Styś, D. 2010. Nondestructive elastic-wave tests of concrete in foundation slab, in the 10th European Conference on Nondestructive Testing, 7-11 June, 2010, Moscow, Russia. 1 p.

Schabowicz, K.; Hoła, J. 2012. Nondestructive elastic-wave tests of foundation slab in office building, Materials Transactions 53(2): 296-302. http://dx.doi.org/10.2320/matertrans.I-M2011845

Schickert, M. 2005. Progress in ultrasonic imaging of concrete, Materials and Structures 38: 807-815.

Shevaldykin, V.; Samokrutov, A.; Kozlov, V. 2003. Ultrasonic low-frequency short-pulse transducers with dry point contact. Development and application, in International Symposium Non-Destructive Testing in Civil Engineering (NDT-CE), 16-19 September, 2003, 
Berlin, Germany. Proceedings on BB 85-CD, V66, Berlin.

Soutsos, M. N.; Kang, T.; Khalid, H. A.; Millard, S. G. 2011. The effect of construction pattern and unit interlock on the structural behaviour of block pavements, Construction and Building Materials 25(10): $3832-3840$.

http://dx.doi.org/10.1016/j.conbuildmat.2011.04.002

Stawiski, B. 2012. The heterogeneity of mechanical properties of concrete in formed constructions horizontally, Archives of Civil and Mechanical Engineering 12(1): 90-94. http://dx.doi.org/10.1016/j.acme.2012.03.006
Taffe, A.; Wiggenhauser, H. 2006. Validation for thickness measurement in civil engineering with ultrasonic echo, in 9th European Conference on Nondestructive Testing, 25-29 September, 2006, Berlin, Germany. 8 p.

Zwolski, J.; Bień, J. 2011. Modal analysis of bridge structures by means of forced vibration tests, Journal of Civil Engineering and Management 17(4): 590-599. http://dx.doi.org/10.3846/13923730.2011.632489

Tomasz GORZELAŃCZYK. PhD, Eng, Assistant Professor in the Civil Engineering Faculty at Wrocław University of Technology, Poland. He obtained his diploma in civil engineering at the WUT in 2001. He is working at WUT, Institute of Building Engineering. Research interests: concrete (especially self-compacting concrete), failure of concrete, acoustic emission, and other nondestructive tests.

Jerzy HOŁA. Full professor at the Wrocław University of Technology, dean of the Faculty of Civil Engineering, Head of the Department of General Building Engineering, and director of the Accredited Research Laboratory at the Institute of Building Engineering. He is a member of the following organizations among others: Senate of the Wrocław University of Technology, Council of the Faculty of Civil Engineering, Section of Engineering Construction Materials the Committee of Civil Engineering Polish Academy of Sciences, Committee of Mechanics and Civil Engineering at the Polish Academy of Sciences Wrocław, Science Committee of PZITB (Polish Association of Building Engineers and Technicians), and the program board of the magazine "Builder".

Lukasz SADOWSKI. MSc, Eng, a researcher at Wrocław University of Technology, Poland. He obtained his diploma in civil engineering at WUT in 2007. He is a research assistant at WUT, Institute of Building Engineering. Research interests: concrete (especially concrete floors), corrosion, adhesion, 3D surface roughness topography measurement, nondestructive tests, acoustic techniques, and artificial intelligence.

Krzysztof SCHABOWICZ. PhD, Eng, Assistant Professor in the Civil Engineering Faculty at Wrocław University of Technology. Received his PhD in 2003 at Wrocław University of Technology. Author and co-author of 3 books, over 100 other publications, as well as over 150 research and technical reports. Member of the Polish Association of Civil Engineers and Technicians (PZITB), member of Polish Association of Building Mycology (PSMB). His research interests include concrete, ultrasonic tomography, impact-echo, impulse response, GPR and other nondestructive tests, and artificial intelligence. 